\title{
DIGRESSÕES SOBRE A REPRESENTAÇÃO NA ARTE DO ATOR PROFISSIONAL ELISABETANO
}

\author{
Aline Castaman \\ Doutoranda no Programa de Pós-Graduação em Artes da Cena (PPGADC) na Universidade Estadual \\ de Campinas (UNICAMP). Mestre em Artes Cênicas pelo Programa de Pós-Graduação em Artes \\ Cênicas (PPGAC) na Universidade Federal do Rio Grande do Sul (UFRGS) \\ Email: alinecastaman@gmail.com
}

Resumo

Este estudo pretende discutir a arte dos atores das companhias profissionais elisabetanas em sua relação com a preparação de seus papeis para a apresentação dos espetáculos. A ideia de ensaio não existia e o que vigorava era o estudo privado, no qual o ator se dedicava a identificar as 'paixões' em cada uma das parts - transcrições das falas e "deixas" das personagens. A preparação do ator envolveria técnicas baseadas em um sistema tradicional de transmissão de regras e convenções de elocução e gestos, e na identificação e manifestação das "paixões". Este estudo tem como objetivo valorizar a arte dos atores, além de problematizar a relação hierárquica $\mathrm{e}$ mesmo hegemônica do texto e dos poetas em detrimento do ator. As pesquisas de críticos e teóricos contribuem para fundamentar e mesmo se opor à proposição. Thomas Wright, Alan Badiou, Tiffany Stern e Matteo Bonfitto são alguns dos autores cujas perspectivas contribuem para problematizar a questão circundante a respeito da interpretação dos atores profissionais do período elisabetano.

Palavras-chave

Espetáculo. Ator Profissional Elisabetano. Representação. Passionating.
Abstract

This study attempts to discuss the art of the actors from professional Elizabethan companies regarding the preparation for their roles in performances. The idea of rehearsal would not exist; instead, a private study would be take place. In such study, the actor would have his/ her parts (discourse transcription) in hands and would be dedicated to memorizing his/her lines and "cues" as well as to setting an enunciation mode. Ultimately, the actor would identify the underlying passions to reveal these passions when transposing the play to the stage. The actor's preparation would involve techniques based on a traditional system of transmitting rules and conventions of elocution and gestures, and on the identification and manifestation of "passions". This research aims to value the art of the actors, besides problematizing the hierarchical relation that privileges text and poets hegemony instead of the acting. Actors were responsible for the play transposition. Thomas Wright, Alan Badiou, Tiffany Stern and Matteo Bonfitto are some of the authors whose perspectives help to question the actors perform in the Elizabethan period.

Keywords

Spectacle. Elizabethan Professional Actors. Performance. Passionating. 
A dúvida inspiradora, aquela geradora de conhecimento, me parece ser, ao mesmo tempo em que estimula e suscita incertezas, uma resposta a uma interlocução que a antecede e, que ainda insatisfatória, deixou lacunas que estão ali para serem preenchidas ou, do contrário, simplesmente problematizadas. Estar no século XXI e se propor a refletir como teria sido a preparação do espetáculo e a preparação dos atores profissionais para a apresentação na época de Shakespeare, numa era em que o teatro conquistara lugar notório no que tange às modalidades de entretenimento oferecidas no período e, portanto, uma força privilegiada em termos de público e repertório, é desafiador já que uma análise de caráter fenomenológico não se faz possível. Porém, alguns juízos que circundam como teria sido o teatro elisabetano e que parecem ter se tornado quase intocáveis e impensáveis de serem discutidos, contestados e/ou reelaborados, são responsáveis por motivar este desafio de discussão. Dentre eles, destaco aqueles que envolvem o trabalho do ator em especial. Há outros, mas por ora me dedicarei a provocar algumas ideias que se acomodaram e me incomodaram no decorrer de alguns anos de estudo ao imergir no universo da pesquisa investigativa a respeito da representação no período. Aponto, portanto, duas assertivas das mais instigantes e comumente difundidas para iniciar a problematização: "o ator aprendia um conjunto de regras de elocução, decorava o texto e tinha como função manifestar o papel adequadamente"; ou, "o ator não criava nada, imitava o modo como o tutor lhe passara as indicações de suas falas que deviam ser seguidas impreterivelmente".

Estas declarações estão tão arraigadas na literatura da crítica e da teoria que me percebo estar à margem, acompanhada de ideias des- centralizadoras e externas à ordem dita natural e, claro, com a impressão de que estarei a cometer um ato condenável por querer discuti-las. Porém, não tomo como uma ameaça, e sim como um estímulo potente para encontrar vias de articulação distintas que abram possibilidades outras de pensar o trabalho deste ator, ainda deveras desconhecido. Mas quais seriam os rastros que consigo observar sobre os materiais que foram utilizados para montar o espetáculo e refletir sobre o trabalho do ator?

O intuito desse estudo está em problematizar a questão da representação, da imitação e do estigma que este ator carrega de ter sido como um veículo ou ventríloquo do poeta. Para adensar a argumentação acerca da arte do ator profissional elisabetano me proponho a apresentar algumas particularidades envolvidas na preparação do espetáculo e do ator que tornará este discurso um tanto mais flexível e arejado em relação aos estudos que postulam a hegemonia do poeta e seu texto em detrimento dos responsáveis por fazer a transposição cênica das peças: os atores.

A primeira consideração a ser feita está relacionada à peça, ao poeta e à companhia teatral. Cada companhia precisava de um repertório consistente para se manter nos palcos públicos, mas nem todas possuíam o privilégio de ter seu próprio dramaturgo como no caso da The Chamberlain's Men, com William Shakespeare e colaboradores, ou, a The Admiral's Men, com Christopher Marlowe. O mais comum na época era haver poetas que delineavam argumentos para serem oferecidos a companhias teatrais, as quais, interessadas na futura história a ser tecida, a encomendariam para posteriormente iniciar o processo de preparação do espetáculo. A peça não teria 
sido escrita para ser lida e vendida ao público com uma narrativa acertada na forma de livro como temos acesso hoje. Ela ainda passaria por um longo processo de ajustes e modificações para que fosse finalizada como um manuscrito transcrito para ser vendido. Depois de ser publicamente 'bem-sucedida' nos palcos e anexada ao repertório da companhia, talvez ela pudesse receber tratamento especial para ser compilada e posteriormente vendida, talvez ela jamais viesse a ser compilada. Mas isso não era, de fato, relevante na época. $\mathrm{O}$ importante para as companhias teatrais era resguardar seu repertório para não sofrer o infortúnio de ver suas peças roubadas e montadas por outras companhias, questão essa bastante grave e que afligia qualquer um do meio. $A$ competição era acirrada entre atores, poetas, companhias e teatros.

Investindo um pouco mais nessa questão que envolvia a preparação, é preciso destacar que do argumento apresentado pelo poeta à apresentação do espetáculo, outros manuscritos eram elaborados pelos escribas das companhias para que o espetáculo se efetivasse. Estes documentos ou manuscritos eram transcrições oriundas da peça do poeta e cumpriam funções diferentes e, portanto, deveriam ser manuseados conjuntamente. O Plot, por exemplo, seria a estrutura, o 'roteiro', o plano de ação, das entradas e saídas dos atores, suas deixas, a lista de atores e personagens que cada um interpretaria. O Book ou book autorizado era a história, cena a cena, personagem por personagem, com os nomes dos atores e respectivas personagens que interpretariam. Ou ainda, e mais importante, o livro assinado pelo censor, que garantia que a peça pudesse ser apresentada, assim como os atores que dela participariam. Sendo devidamen- te autorizada, seria possível fazer a transcrição das falas dos atores, para então, distribuí-las. Tais transcrições eram comumente chamadas de Parts, as quais continham as falas e "deixas" de entrada e saída dos atores. Este documento delegaria ao ator a responsabilidade de transpor cenicamente a personagem, sendo que o mesmo não tinha uma relação forte com a história em termos narrativos e que, por conseguinte, a noção dos atores sobre o todo da história era vaga até antes de encontraremse para fazer uma primeira leitura - caso tivessem tempo para isso.

Duas eram as noções fundamentais para que atores fossem admitidos por uma companhia: o sistema de deixas e o Passionating, conhecida como sendo a arte de interpretar do ator elisabetano que abrangia uma série de conhecimentos, entre eles, identificar e manifestar as paixões da personagem. $O$ ator tinha em mãos, então, apenas as falas da (s) personagem (s) que representaria. Essas seriam encaixadas às partes correspondentes das outras personagens durante o espetáculo. Logo, os atores teriam acesso ao todo da peça no próprio espetáculo. Era no palco que a unidade da história seria construída pelos atores. Ao final de uma temporada, que se estendia de abril a setembro, o número de personagens interpretadas variava entre 30 e 40 . Os palcos públicos abriam suas portas seis dias na semana. Espetáculos diferentes formavam o seu atrativo. Londres, no final do século XVI, já dispunha de oito teatros e centenas de atores disputando um espaço para serem notados e finalmente se estabilizarem, tornando-se membros de alguma companhia. $\mathrm{O}$ ator profissional, familiarizado ao exigente ritmo de trabalho, dedicaria, em seu estudo privado, algumas horas do dia para preparar seu papel - ou papeis, no caso 
de interpretar mais de uma personagem num mesmo espetáculo. Não havia ensaio. Aconteciam reuniões para as coreografias das cenas de luta. De resto, havia uma mobilização coletiva para que tudo estivesse organizado para os atores subirem ao palco às 14 horas.

Feitas algumas elucidações importantes, seguimos a discussão para pensar o trabalho do ator profissional elisabetano, uma vez que a subordinação ao texto parecia imperativa, desde que levemos em consideração as particularidades envolvidas no processo de montagem do espetáculo e no modo de preparação dos atores para entendermos como se dava essa relação com a peça escrita. Certo. Havia um texto, que era pensado, estruturado, elaborado para ser transposto cenicamente, por atores. Um texto cuja forma e conteúdo abrangiam convenções que perpassavam as regras da oratória quintiliana e ciceriana entrelaçadas à tessitura das peças. Na dramaturgia shakespereana em especial, já avançava e ampliavase formalmente, atitude antes impensável de inovação. Shakespeare era ávido leitor e autodidata que trabalhara como ator e sabia da experiência e exigências de estar no palco. Sua sagacidade não poderia deixar de avaliar que as mudanças na escritura, reverberariam consequentemente no modo da representação e ampliaria a esfera de possibilidades, uma vez que a tradição das figuras alegóricas do teatro medievo dava lugar a personagens de maior grandeza e profundidade de caráter. Exigindo, supostamente, atores que pudessem corresponder à amplitude dessa esfera. Ao escrever para eles, com eles e outros dramaturgos, os quais alguns deles eram também atores, compunham estratégias enredadas na tessitura das cenas.

O estudo privado a partir das parts, abar- cava identificar as paixões, estudar as ênfases e gestos para, no palco, o ator manifestar a personagem. Tal estudo era o que podemos associar hoje a um ensaio que em nada se aproxima de ser coletivo. Não há registros de qualquer espécie de reunião entre os atores para se trabalhar os diálogos entre eles. Havia sim, uma primeira leitura em conjunto, e, encontros para que as cenas de luta, por exemplo, pudessem ser coreografadas. Há, porém, uma característica fundamental no trabalho desse ator: no estudo privado, os atores poderiam contar com a ajuda de um tutor - que poderia ser o próprio poeta ou outro ator da companhia - a colaborar, a transmitir as particularidades concernentes às falas. Ou seja, o ator apreenderia tais particularidades pelo processo de imitação ou pelo modo que este tutor se ocuparia em enunciar as falas da personagem. "Hamlet - Por favor, repitam a fala como a pronunciei, com língua bem ágil. Se vocês as berrarem como muitos atores fazem, meIhor é chamar o pregoeiro público pra repetir as linhas" (Shakespeare, 2015, p. 56). Havia, portanto, um saber transmitido via dramaturgia e via imitação no estudo privado, porém, é no hit et nunc da cena que o Passionating poderia se manifestar.

A problemática desse ator está no como lidar com a representação. Passa pela questão de tornar algo vivo ao manifestar as paixões que nas parts são exigidas a ele identificar. Mas antes, é iniciado na arte da representação pela imitação como sendo um processo no qual Ihe são transmitidas técnicas que se afastam de uma teoria aplicada e utilitária na qual ele se servirá intelectualmente para emitir um discurso insípido, automático e/ou desprovido de estilo. Imitar não significa apenas a aparência das coisas. A imitação pode ser compreendida 
como um modus operandi do ator que abarcava um processo de aprendizagem carregado de conhecimento. O trabalho contínuo ao lado de um tutor poderia servir como ignição para gerar conexões entre processos interiores e exteriores ampliando as potencialidades expressivas do ator? Com o passar dos anos, o ator profissional, imerso num ritmo de trabalho tão acelerado como era o da cena londrina, já acostumado com tramas eloquentes e personagens que se despediam do caráter alegórico para adensar em profundidade, poderia encontrar um espaço de interpretação que o propiciasse a exceder as convenções e regras subjacentes ao Passionating, conduzindo-o a acessar outras variações expressivas? Sirvome aqui das palavras do pesquisador e ator/ performer Matteo Bonfitto (2003, p. 91) em $O$ Ator Compositor, o qual as emprega num contexto bastante distinto do período elisabetano, entretanto, muito iluminador no que concerne à questão da imitação e, por isso, apropriado para aproximá-los. Bonfitto discorre a respeito das centenas de combinações que o ator oriental de Kabuki teria a disposição para escolher, num modelo que, aparentemente, poderia ser entendido como imutável. Esclarecendo, portanto, que dentro desse universo calcado na imitação e de numerosas combinações, cada ator encontraria os seus meios para manifestar suas singularidades. Haveria ali um espaço para variações expressivas.

Mesmo com uma tradição, a priori, pouco maleável com relação à transmissão das regras de interpretação, a noção de Passionating para os atores elisabetanos parece abranger uma centelha de mobilidade interna que, também a priori, pode conciliar a rigidez da forma com a disposição livre de acomodar nuances e ritmos distintos que, o verso e a prosa das pe- ças dispõem sob o aperfeiçoamento do conjunto entre vox, vultus e vita ${ }^{1}$ que Thomas Wright (1620) teria observado e explicado no livro The passions of the minde in generall. O filósofo e escritor inglês Thomas Wright (15??-1624) publicou, em 1601, a primeira versão de seu livro The Passions of The Mind que, logo mais, em 1604, seria reeditado e ampliado para se tornar The Passions of The Minde in Generall. O tratado contempla uma investigação curiosa, e por vezes caótica, sobre o que o autor teria chamado de "os movimentos da alma". Nele, o termo passion (paixão), do latin passio e do grego páthos, estaria relacionado ao destempero ou às perturbações da mente e tem seu sentido perpassado por saberes como a filosofia, a psicologia e a medicina, para fundamentar como as paixões se manifestariam no homem e quais os meios utilizados para evocá-las, em especial por oradores e atores.

Transitar entre uma paixão e outra, tal como o ator pode alcançar e ao mesmo tempo manter-se alheio a elas, não ser abarcado e/ou sucumbir a elas. De acordo com Wright (1620), essas manifestações são nomeadas passions, embora ele as considere atos, ações do poder sensível, ou faculdades da alma, e para representá-la(s) haveria duas regras que deveria(m) ser seguida(s) pelos atores: estar atento às ações e às reações dos homens diante das mais variadas circunstâncias; observar o quê e como eles se conduziriam quando em situações de alegria, tristeza, ira, medo e em seguida, abstrair os excessos, os defeitos, a inconstância exorbitante de seus atos. No quarto livro, o autor inglês discorre sobre o momento em que as paixões se tornariam ações e define o que compreendia como ação:

$1 \mathrm{Voz}$, gesto e vitalidade. 
Por ação entendemos tanto uma certa eloquência evidente, como uma eloquência do corpo, ou uma agradável beleza em recitar ideias, como também uma imagem externa da natureza interna ou uma sombra de afeições, ou três matrizes que partem de uma mesma fonte, chamadas voz, gesto e vitalidade - voz, compleição e vida; [...] A ação, sem exceção, é um comedimento natural ou artificial, uma aptidão, uma modificação ou composição vocal, compostura, um movimento corporal originando notável paixão e capaz de comover qualquer pessoa. (Wright, 1620, p. 176). Tradução da autora.

Para Wright, o ator é quem seria capaz de identificar, compreender e manifestar os estados da mente, de transitar entre esses estados, controlá-los e não se deixar ser tomado ou abarcado pelas inconstâncias quando no palco. Ao ator cabia reunir e elaborar artística e intelectualmente a construção do papel e transformá-lo numa personagem criada, através de um conjunto de competências que implicavam no estudo de uma técnica, que ele, no momento da interpretação, se serviria dela para governar as paixões e não se deixar afetar. O Passionating estaria também relacionado a expressões de qualidades calcadas numa dramaturgia rica em ornamentos linguísticos e que, no que concerne ao trabalho do ator, permitia ampliar as possibilidades de sua arte e dar lugar ao aprofundamento de seus papéis. Servir-se de gestos, utilizar uma linguagem calcada em alguns preceitos - sobretudo os que implicavam o estilo - tornou-se uma arte aperfeiçoada pelos atores.

A pesquisadora Tiffany Stern (2004), em Making Shakespeare: the pressures of stage to page, comentando Wright, infere a respeito de como esse reconhecimento das paixões, de suas transições era, no trabalho do ator do pe- ríodo, congruente à construção dramatúrgica e refinado no estudo das parts via instrução:

Transições visíveis de uma paixão mais extrema a outra dentro de um discurso eram altamente consideradas - e por isso eram escritas dentro do texto. Nas peças de Shakespeare elas podem ocorrer quando a prosa dá lugar ao verso, quando a linguagem 'simples' dá lugar à linguagem 'complexa' ou quando linhas sonoras e longas dão lugar a sentenças mais curtas e em staccato. Estas são algumas das características que um ator identificaria em sua parte enquanto trabalhasse junto ao instrutor. (Stern, 2004, p. 80). Tradução da autora.

Aos atores, conforme Stern (2004, p.81), que agiam dentro desse corpo de regras ou a partir dele, cabia realçar suas interpretações com combinações outras. Acreditava-se que uma paixão cedia a outra com enorme facilidade, pois se pensava que as paixões eram alcançadas pelo intelecto, pela velocidade e violência, sendo que transições entre paixões eram altamente consideradas.

Não seria um insulto ao ator declará-lo um veículo do poeta, tomá-lo como um ventríloquo enunciador de discursos? Pressupô-lo menos criativo, pouco inventivo ou inexpressivo confiando ou aludindo o encanto da representação somente à peça? Não estariam estes atores passíveis a atualizar a forma, na medida em que se apropriavam da técnica, de cada palavra memorizada dentro de cada verso e sonoridade delineada, das regras e convenções disponíveis a serem seguidas e reconfiguradas, a partir do conteúdo? Por vezes penso nas personagens criadas no palco pelos atores, os quais tinham uma vaga noção da história completa e que se somava à ausência de ensaios coletivos. Para os atores da companhia de Shakespeare, a loucura diária e 
semanal de interpretar diversas personagens, seja no Globe ou para a corte em ocasiões de caráter particular, parece ser muito exigente. Penso no quanto a harmonia e a desarmonia poderia vir a contribuir para as transformações na rotina fervilhante de uma companhia. Quais seriam os descontentamentos frequentes dos atores e as indisposições de Shakespeare para com eles?

Imagino que nem todos os atores apreciavam constantemente a subordinação ao texto e, que da entrega das parts, num momento ou outro, evocar metáforas, analogias, trocar palavras, inserir onomatopeias, ou seja, exatamente por dominar o Passionating e todas as suas regras implicadas, por ter propriedade em dar suas falas, provocavam-se, escapando da fixidez decorada da fala, para jogar com outras possibilidades, descobrir nuances novas desde que se mantivessem atentos as deixas e não comprometessem as cenas que se encaixavam uma a uma pelo sistema. Ao que chamei de jogar, me remeto à ideia que o jogo se dá entre participantes, entre os componentes do acontecimento teatral. Entre ele e o público, entre ele e seu parceiro de cena, com ele e suas capacidades. $O$ ator, por excelência, está atento a isto, sente isso, sabe disso. Pode vir a mobilizar-se pelas questões que movem a personagem que interpreta e não abrir mão de manifestar sua subjetividade através da interioridade da personagem. A personagem é atualizada pelo ator quando este transforma em ações as questões que a movem. $O$ texto não é mais texto, transformou-se em ação, música, vozes, ideias, sensações, espaço, figurino, transformou-se em cena, espetáculo, Teatro. Como afirmara o filósofo Alan Badiou (2002) em Pequeno manual de inestética:
O Teatro pensa. [...] O arranjo dos componentes produz diretamente ideias. Essas ideias são ideias-teatro. Só podem ser produzidas no teatro. $\mathrm{E}$ nenhum dos componentes isoladamente está apto a produzir as ideiasteatro, nem mesmo o texto. A ideia advém dentro da representação e por ela. (p. 97)

Representação é re-presentificar. Não compete ao texto dar conta da representação, do fenômeno teatral. O texto é só mais uma ignição para a materialização de estados, porém incompleta. Ele é um dos componentes que reunido com outros, no palco, tece uma rede de signos, sensações, efeitos, encontros, relações que qualificam o acontecimento como possível instaurador de experiência. "A arte do teatro é decerto a única que tem de completar uma eternidade com o que lhe falta de instantâneo" (Badiou, 2002, p.99). A ideia de subordinação ao texto implica uma matriz original. Supõe-se a existência de uma matriz verdadeira que teria sido escrita e seguida strictu sensu. Porém, várias são as matrizes responsáveis pela transposição cênica. Sejam os quartos e fólios do poeta, sejam os manuscritos transcritos para a montagem como já explicitei acima, realizados pelos escribas (plotter/prompter) e construídos pensando na organização cênica a partir daquela matriz que lhe fora entregue.

Assim como as parts, caso alguma modificação acontecesse, caso o dramaturgo propusesse mudanças em determinados diálogos, falas ou solilóquios, este se dirigiria diretamente ao ator correspondente de tal personagem e entregaria a part ou parts com as reformulações. Ou seja, como garantir uma matriz original e verdadeira se o processo de construção da peça se delineava no entrelaçamento de sugestões criadas antes do espetáculo, e/ ou a posteriori, no manuseio e enquadramen- 
to de cada pequeno fragmento que reunidos edificavam no palco o resultado de um 'texto outro', que concerne ao do espetáculo, distanciado das proposições iniciais? Vejamos na passagem em que, na tragédia de Hamlet, a personagem-título sugere a um dos atores da companhia a inserção de um novo fragmento cujo conteúdo serve aos propósitos de Hamlet de causar algum efeito sobre Claudius, o suposto assassino de seu pai:

Hamlet - Amigos, sigam-no. Amanhã assistiremos uma peça. [530] [Ao primeiro Ator] Meu velho amigo, estás me escutando? Vocês podem representar A Morte de Gonzago?

Primeiro Ator - Sim, senhor.

Hamlet - Será amanhã de noite. Poderia, se necessário, decorar uma fala de umas doze ou dezesseis linhas, que [535] escreverei para intercalar na peça?

Primeiro Ator - Sim, meu senhor. (Shakespeare, 2008, p. 48).

As considerações aqui discutidas não têm a pretensão de sobrepor o ator ao texto. De fabricá-lo como um sujeito autoral, livre e sem restrições para improvisar a partir do texto. O texto, ou melhor, suas parts eram, de fato, sua referência. E não as seguir, mais do que prejudicar o sistema de deixas comprometendo a cena e mesmo o espetáculo, realizando improvisações de conteúdo ofensivo, poderia levar a derrocada da companhia, uma vez que os conteúdos das improvisações, claramente, não recebiam a assinatura do censor. Mas com o tempo tornou-se muito difícil tomar conta de tantas peças. No apogeu do teatro inglês, de 1585 a 1642, o número de atores que se profissionalizaram dedicando-se exclusivamente à arte teatral, formando companhias e com poder aquisitivo para firmar os pés no cenário londrino, aumentou consideravelmen- te. Aumentou também a competitividade entre os dramaturgos, os quais escreviam peças e mais peças que deveriam se ajustar ao gosto da companhia, dos censores e do público. Do contrário, a companhia não compraria, o censor não aprovaria, ou ela não permaneceria no repertório. Percebe-se que há uma conjuntura de condições que precisavam ser acertadamente articuladas para que um espetáculo pudesse se efetivar no palco e se manter no repertório para ainda, posteriormente, receber outros tratamentos, dependendo de quando e onde seriam reapresentadas.

Porém, considerar os atores como coadjuvantes, exteriores a um processo que se constituía no conjunto e interação entre seus elementos que engendravam a montagem no palco, parece capcioso. Como toda a encenação, articulações são pensadas, manejadas, organizadas, mas controlar um fenômeno que por natureza é da ordem do imprevisível é, particularmente, querer impor, forçosamente, uma ideia que extrapola a ideia do que seja Teatro. É contar com a incompetência dos atores frente ao acaso, ao presente que se lhe apresenta e que não pode ser de todo fixado. Há exigências inerentes desse ofício deflagradas no ato do acontecimento. E delegar ao ponto 2 a responsabilidade de dar conta de todos os brancos, os imprevistos, os acidentes, e mesmo as falas, sendo ele um dos membros da

2 O prompter teria acumulado algumas funções dentro da companhia. Era compreendido como o provável escriba e/ou plotter da companhia, o qual tinha a função de transcrever as peças e partes, ou como o responsável por controlar as entradas e saídas dos atores de cena asseguradas no Book e que estavam sob sua vigilância, pela sua própria função de ponto. Era uma figura estratégica para a companhia e para os atores. Dentro e fora do palco ele se mantinha atento às entradas e saídas dos atores de cena, às falas e deixas dos atores, possuindo total acesso ao Book e ao Plot, e, portanto, mantinha os livros mais importantes de preparação de uma peça sob sua responsabilidade. Depender dele o tempo inteiro seria algo pouco provável. 
companhia com maior acúmulo de funções, é subestimar o ator. Por isso, compreendê-los como colaboradores, ao lado de cada um dos outros membros da companhia, me parece mais assertivo e menos ditatorial, como infere Stern (2004).

Ademais, a representação fundamentada nestas particularidades apontadas não foi estéril. Robert Tarlton, William Kempe, Richard Burbage, Edward Alleyn, Robert Armin e centenas de outros tem seus nomes lembrados justamente por terem sido aclamados como os mais célebres atores de sua época. Apostas eram realizadas para decidir qual deles interpretaria melhor o papel. O que indica haver parâmetros para se reconhecer as distinções entre uma representação e outra. Entre quando se instaura uma experiência e quando não acontece nada.

Em que medida se permitiu pensar sobre a possibilidade do ator profissional elisabetano em criar? É possível afirmar que o ator criava a partir das parts? Criar no sentido de extravasar as convenções, de variar expressivamente, de transformar em ações as paixões instadas no papel. Criar distanciado da ideia de originalidade, da ideia de gênio e de sua assinatura, do seu ineditismo como valores regentes e primordiais para se designar " 0 " artista. E mais aproximado da ideia de um vir a ser que se iniciaria pelo processo da imitação e que permitiria ser ampliada pela sua capacidade perceptiva. Criar no sentido de suscitar possibilidades que poderão gerar disposições internas e externas, a fim de conquistar determinadas qualidades expressivas na representação. Tais qualidades não estão subordinadas às parts, e não compete a elas descrevê-las. Compete ao Passionating dos atores, "esses bandidos bem-amados", como atribuiu Badiou (2002, p.
99). Desvendá-las, representá-las, por fim, saber fazê-las. $O$ ator profissional elisabetano há muito tempo parece se encontrar à margem, ironicamente descentralizado. Teria sido ele, naquele tempo, assim, tão pouco importante?

Referências

BADIOU, Alain. Pequeno manual de inestética. São Paulo: Estação Liberdade, 2002.

BONFITTO, Matteo. O ator compositor. As ações físicas como eixo: de Stanislávski a Barba. São Paulo: Perspectiva, 2003.

SHAKESPEARE, William. A tragédia de Hamlet, Príncipe da Dinamarca. São Paulo: Companhia das Letras, 2015.

STERN, Tiffany. Making Shakespeare, the pressures of stage to page. New York: Routledge, 2004.

WRIGHT, Thomas. The Passions of the Minde in Generall in Six Bookes (1620) Thomas Dewe. Impresso por Augustine Mathewes and Anne Helme. Reprodução do original em Folger Shakespeare Library. London: EEBO Editions, s/d.

Recebido: 28/12/2015 Aprovado: 19/09/2016 